\title{
USE OF MOBILE DEVICES FOR E-LEARNING IN GEOMATICS
}

\author{
H. Mills \\ School of Civil Engineering \& Geosciences, Newcastle University, NE30 1RU Newcastle upon Tyne, UK - \\ (henny.mills@newcastle.ac.uk)
}

Commission VI, WG 1-3

KEY WORDS: e-learning, mobile devices, student learning

\begin{abstract}
:
For the last 4 years, the School of Civil Engineering \& Geosciences at Newcastle University, UK adapted mobile devices as learning approach only for undergraduate within Geomatics. All incoming students were given a mobile device as learning tool, which was supposed to be there main way to accessing teaching material. This paper will present how students adopted the mobile devices and how their learning has changed using mobile devices. It will highlight which apps can be used in a Geomatics teaching environment to engage students in their learning and teaching environment. The paper will furthermore look into apps which help students within the area of Photogrammetry and Remote Sensing, such as the Autodesk 123D catch up or the Remote RDP app to remotely control surveying instrumentations, such as laser scanners. Those apps are easy tools to engage students within digital learning environment which the students are familiar with. The paper will show how students embrace the technology but also current limitation of using those within Higher education establishments, such as sufficient Wifi and student support for using mobile devices.
\end{abstract}

\section{INTRODUCTION TO MOBILE DEVICES IN HIGHER EDUCATION}

\subsection{Introduction and background}

The rapid development in computing technology over the last decade has impacted the way teaching is delivered. Technology developments, ranging from software applications, social media and hardware, have altered the way students receive and gain their knowledge and learn (Fallon, 2013). The latest technology evolving tablet has been pushed and marketed by their manufacturers as possible device to revolutise and moderinse teaching and change the way informations are distributed (Fallon, 2013) (Martin and Ertzberger, 2013). Students quickly realised that mobile devices, such as tablets allow the learning and the access of learning material anywhere and anytime (Ting, 2013), (Martin and Ertzberger, 2013) , (Tapia-Moreno et al., 2012). The majority of students, studies quote between 80 and $90 \%$, own a smartphone and use them anywhere to access social media but also at the University environment to access those resources (Nagel, 2013) (Marinagi et al., 2013) (Welsh and France, 2012, Rockinson-Szapkiw et al., 2013).

The enjoyment and ease of use of mobile devices, lend those devices to use in higher education (Molnár, 2013). Different use and applications of the internet, such as social media have been adopted by students for their learning and their peer-support structure. Social media apps, such as YouTube and employed for their revisions and peer to peer conversations to support peer communication and learning. The YouTube app is one of the most widely app, which is seen by students as an innovative and efficient learning medium. It is adopted by students to gain more understanding in particular of common subject such as maths and computing.

The development and use of mobile devices has been be accepted by higher education establishment as a teaching tool as well as their provision for interactive learning in particular subjects. As such, apps suitable for learning and teaching in
Geomatics, Photogrammetry and GIS are becoming more and more available and should be integrated in the teaching of the $21^{\text {st }}$ education.

The paper will discuss how the School of Civil Engineering at Newcastle University adopted mobile devices into their teaching and how this change in teaching delivery was accepted and take up by students. The further it will present a selection of apps, which are suitable for teaching within Geomatics subject areas.

\section{PIONEERING EDUCATION: ADVANCED RESOURCE FOR LEARNING}

Early in 2011 the School of Civil Engineering and Geosciences at Newcastle University recognized the need to innovate the delivery of teaching material such that it was better aligned with developments in student's interest and approach to learning. Mobile technology, social media and e-learning has become a very important tool for students for their students experience, communication amongst peers, and exchange of knowledge but are also part of their learning and support the organization of their studies and time throughout their university life.

The modernisation of teaching methods was recognised as essential to help foster the development of new pedagogical approaches and to improve the student experience. In assessing the highly proficient IT skills of incoming "Playstation generation" students, the potential to improve the pedagogical approach by harnessing the student's familiarity with mobile devices to enhance their engagement in their studies was identified. Mobile devices and e-learning have become central to the students learning and their peer-support structure. Lecturers have also employed different multimedia in education for many years, ranging from video, photos, and animated slides to improve the teaching delivery and increase student engagement. Changes in multimedia tools to social media, such as blogging, wikis and social networking are also been adopted to enhance education and to utilise tools which are familiar to the students. 
The School of Civil Engineering and Geosciences PEARL (Pioneering Education: Advanced Resource for Learning) project is revolutionising teaching delivery and enhancing the student experience across the School of Civil Engineering \& Geosciences (CEG) including geomatics. With the beginning of the 2012/2013 academic year, the School of Civil Engineering \& Geosciences implemented Project PEARL (Pioneering Education: Advanced Resource for Learning) for all incoming undergraduate students reading Civil Engineering and Geomatics. This consisted of issuing 35 Geomatics and 90 Civil Engineering students with mobile tablet devices. Project PEARL is revolutionising teaching delivery across the School by providing staff and students with a mobile device to access on-line lecture and practical materials.

CEG invested around $£ 45,000$ annually into the purchase of 145 Android tablets since 2012 to enhance the student learning experience for students joining the School. This was paralleled with a step change in the delivery of teaching material into electronic form only. The mobile devices are the main way for students to access lecture and practical materials, allowing them to access their handouts and notes on a $24 / 7$ basis. An initial trial study, performed with a dozen devices in AY 2011-12, had showed that mobile devices had enhanced the student experience through more flexible learning, for example group and project work was better facilitated. It also demonstrated that the adoption of mobile devices minimised the need for costly distribution of hardcopy handouts during lectures and practicals.

Additionally, more and more students are purchasing mobile devices themselves and use them actively as part of their student life. CEG actively supports and encourages the use of mobile devices as an integral part of the student's learning. Project PEARL has concluded that mobile devices can indeed enhance the overall student experience, creating a more flexible learning approach for a 21st Century student body.

As all students currently use the same mobile device, they can engage with each other as soon as arriving at Newcastle University. This commonality amongst the students helps them to identify with CEG and their peers, creating a community spirit. The full embracing of mobile devices improves the student experience beyond the simple and mundane accessing of lecture materials, to allow the students a sense of engagement in their degree programme and hence also contribute to student retention.

The use of mobile devices by students will undoubtedly grow in coming years, and projects similar to PEARL are implemented by other Universities.

PEARL researched into the delivery and distribution of electronic-only teaching materials via mobile devices, principally tablet computers, concluding that mobile devices can indeed enhance the overall student experience, creating a more flexible learning approach.

\section{STUDENT ADOPTION OF}

This study investigate how the use of the mobile devices can be fully integrated into the learning environment and help to improve the teaching delivery by allowing students to engage closer with their University peer and their lecturers. Feedback from students showed that the students very much appreciated lecture interaction, as it allowed them to self-assess their knowledge and led to better engagement in lectures.

As the primary users of the mobile devices are students, it was essential to involve students centrally to the project and allow them feedback on the project. The student experience is enhanced through more flexible learning; group and project work better facilitated.

Students were questioned at different stages during an academic year about their adoption of. The results if the student's responses are shown below.

A large majority of students, over $90 \%$ over students felt that the use mobile devices benefits their students experience and enhances their learning and teaching at university (Figure 1).

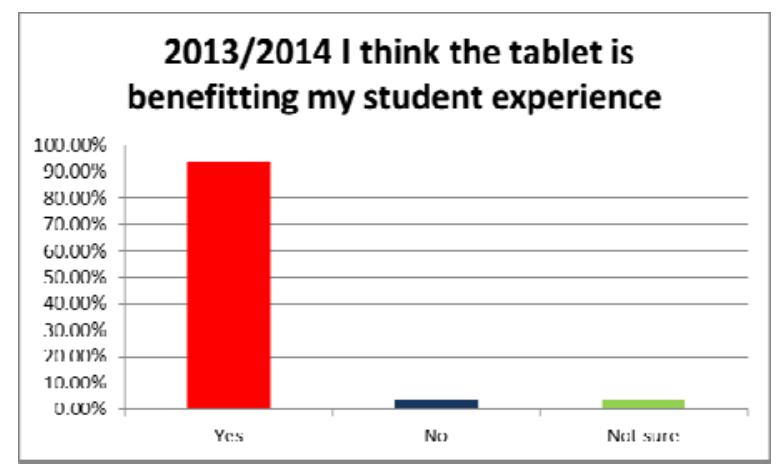

Figure 1. Mobile devices effect on student experience

It shows that students use mobile devices at part of their students' life and have accepted these for it (Figure 2). To further analyse the use of mobile devices in their learning, it showed that not all students on a daily basis, but overall very regularly.

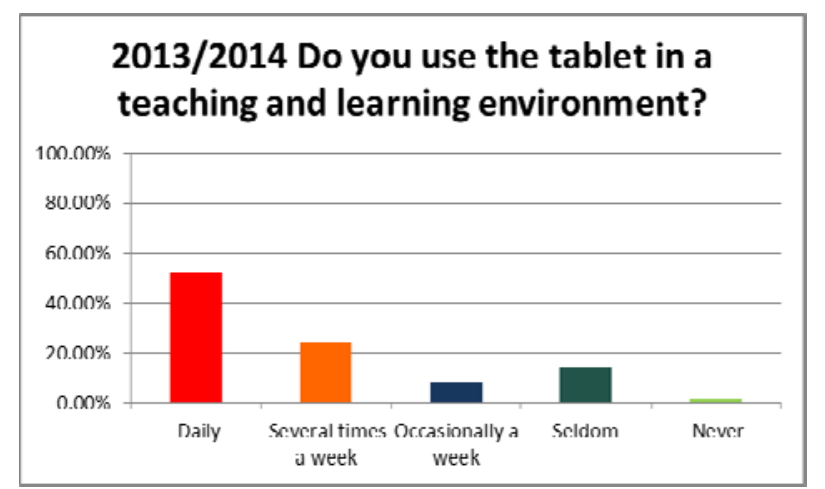

Figure 2. Use of mobile devices by students

About $15 \%$ of the students had not taken to mobile devices and were using them rarely for their learning.

When queried about their use in lecture, the majority of students answered that they prefer the teaching in digital format and would not prefer to use paper handouts anymore (Figure 3). 


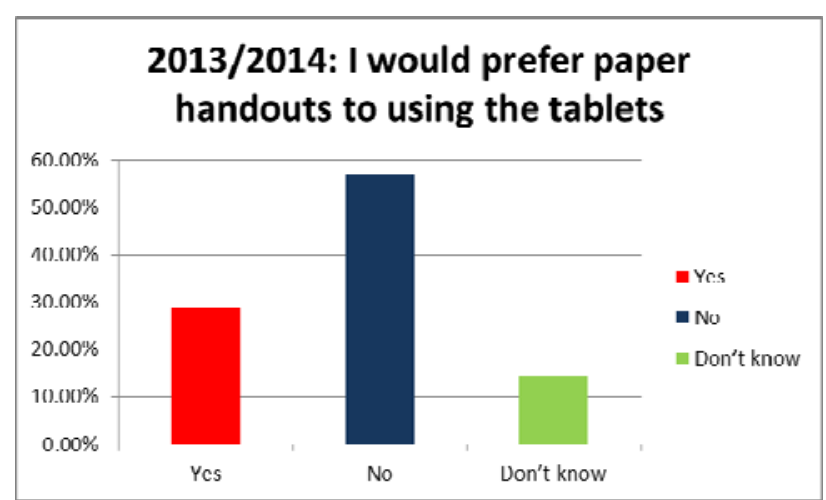

Figure 3. Digital vs. hardcopy handout preference by students

It was encouraging to see that students have adopted mobile devices quickly and have adjusted their way of traditional paper handouts to digital handouts only.

The use of mobile devices has been adopted by students in a wide range life at University, such as for accessing lecture notes and following lectures, accessing the student management system etc. (Figure 4).

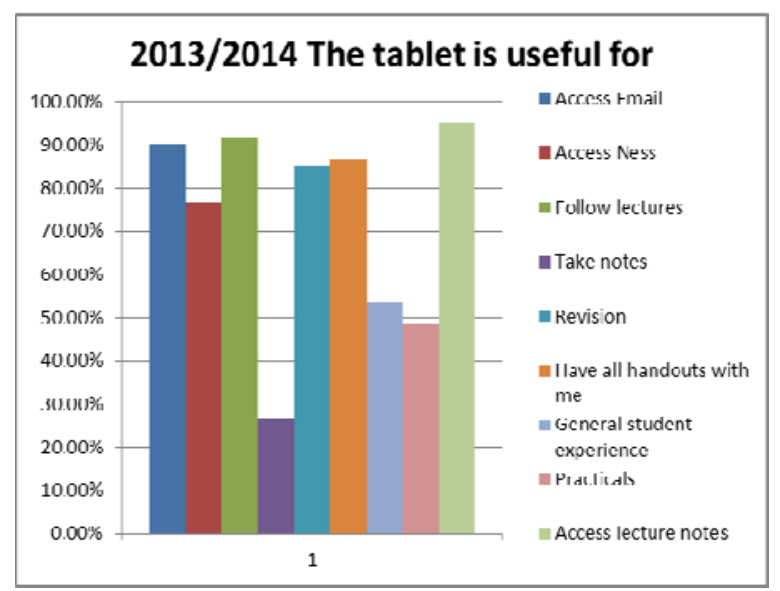

Figure 4. Use of mobile devices by students within the University

Unfortunately many students fail to use mobile devices to take notes on, which is one of the fundamentals of learning at a higher education university. It shows that while students generally accept mobile, improvements and adaptability of mobile devices needs to be improved to see that students devices use them for every aspect of learning and.

\section{MOBILE DEVICE APPS SUITABLE FOR GEOMATICS TEACHING}

This study further investigate the potential of a variety of apps which facilitate the integration of mobile devices into a Geomatics teaching environment.

Several apps have been made available at Newcastle University to support and ease the use of mobile device for teaching and learning.

\subsubsection{Newcastle University app:}

Newcastle University released an app specific for the student needs in 2014 in time for the new academic year to start. This underlined the recognition of the University administration that mobile devices play now a central part in the students' life and are part of their experience at University. With the help of the app, students are able to access their timetable, exam schedule, printing credit, library loan at $24 / 7$ but are also possible to locate computer cluster with available computers, look for staff details and access a campus map. Many Universities will now offer specific apps to support their students' life within their institution.

\subsubsection{Responseware app:}

Newcastle University invested into 1000 licenses of the Responsware app. It enables students to participate in lecture interactively by answering questions presented during a lecture. As PowerPoint slides with e.g. multiple choice question are presented in the lecture, students can answer the question on their mobile device using the Reponseware app. It presents a good way of engaging students in lecture but also testing their knowledge and understanding of the material presented in real time. This benefits of Responseware are highlighted in Figure 5, presenting the students opinion of the app.

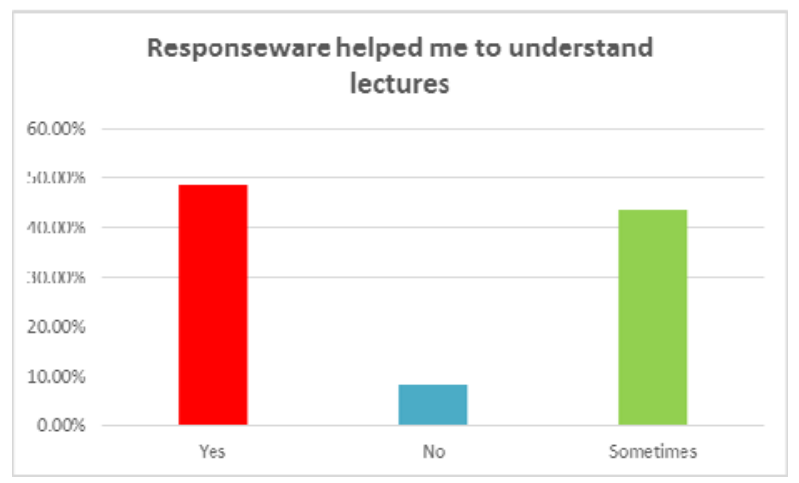

Figure 5. Responseware app usefulness for students

\subsubsection{Geoviewer}

The app Geoviewer has been used within CEG in practicals for remote sensing. It allows to students to view raster and vector imagery and at the same use measurement tool and online base maps (Figure 6). This app is suitable to familiarise students to remote sensing and allow them to understand how to view and interpret a remote sensing imagery. The data for the practical is available to the students via Blackboard and each student can view the imagery independently in a practical without requiring extra computing resources.

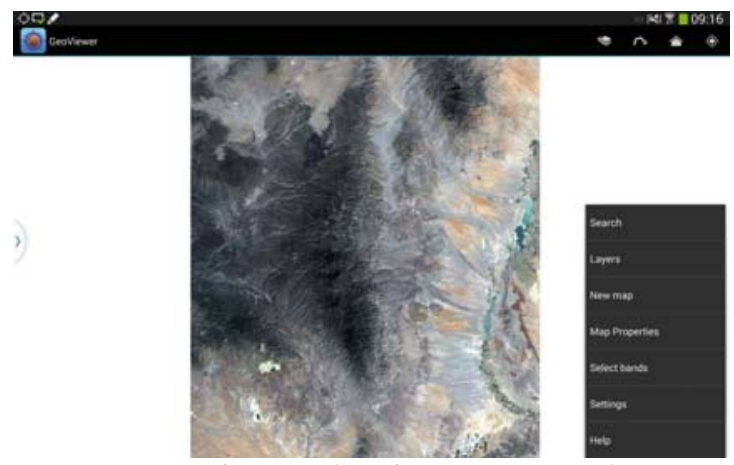

Figure 6. Geoviewer app example

\subsubsection{3 catch}

Autodesk released the 123catch app, as a simplified tool to create 3D point clouds. Within he app, photos of the object can be taken using the camera of the mobile device. The photos are uploaded to the 123 catch server and within minutes a full 3D model is returned. The ability for each students to create their 
own 3D modelling with their mobile device allows the animate photogrammetry and enables all students to apply their photogrammetry understanding by using this app. Being a an automated 3D model generation tool, it is very sensitive to incorrect data or insufficient overlap, which shows students the need to apply their photogrammetry knowledge to this app.

\subsubsection{Remote RDP}

For laserscanning practicals the remote RDP app has been allowing us to make the Leica P20 more accessible to more students. The Remote RDP app allows to take control of the P20 laser scanner via a mobile device, when the menu screen of the laser scanner is presented on the screen of the mobile device and can be controlled from there. With the bigger screen on mobile device, more students can follow the menu choices and the laser scanner can also be presented during lectures.

The selection of apps presented here, shows that mobile devices can play an active role within the teaching of photogrammetry and remote sensing. It allows students to work independently but also for each student to experience applied photogrammetry or remote sensing.

\section{CONCLUSION}

The study concluded that the integration of mobile devices into the teaching environment allows students to better engage with their studies and improves their students' experience. A variation, but by no means complete list, of apps were presented which can be integrated into the teaching of photogrammetry and remote sensing. Additionally, students' feedback was presented on the use of mobile devices for their learning, showing that students adopt mobile devices for the life at University and belief it improves their student experience. The use and possibility of implementing mobile devices in teaching within Geomatics will grow over the next years, with more subject specific apps becoming available and mobile devices becoming more widely available amongst students.

\section{REFEENCES}

FALLON, G. 2013. Young students using iPads: App design and content influences on their learning pathways. Computers \& Education, 68, 505-521.

MARINAGI, C., SKOURLAS, C. \& BELSIS, P. 2013. Employing ubiquitous computing devices and technologies in the higher education classroom of the future. Procedia- Social and Behavioral Sciences, 73, 487-494.

MARTIN, F. \& ERTZBERGER, J. 2013. Here and now mobile learning: An experimental study on the use of mobile technology. Computers \& Education, 68, 76-85.

MOLNÁR, G. 2013. New Learning Spaces? M-Learning's, in Particular the iPad's Ptentials in Education. Internationa Journal of Interactive Mobile Technologies, 7.

NAGEL, D. 2013. Android will extend dominance over all devices through 2014 [Online]. [Accessed 4/7 2013].
ROCKINSON-SZAPKIW, A. J., COURDUFF, J., CARTER, K. \& BENNETT, D. 2013. Electronic versus traditional print textboosk: A comparison study on the influence of university students' learning. Computers \& Education, 63, 259-266.

TAPIA-MORENO, F. J., VILLA-MARTINEZ, H. A. \& LOPEZ-MIRANDA, C. A. 2012. Elaboration of Statistics Learning Objects for Mobile Devices. Internationa Journal of Interactive Mobile Technologies, 6, 51-54.

TING, Y.-L. 2013. Using mobile technologies to create interwoven learning interactions: An intuitive design and its evaluation. Computers \& Education, 60, 1-13.

WELSH, K. \& FRANCE, D. 2012. Smartphone and fieldwork. Geography, 97, 47-50. 